\title{
Long-term pain outcomes for recurrent idiopathic trigeminal neuralgia after stereotactic radiosurgery: a prospective comparison of first-time microvascular decompression and repeat stereotactic radiosurgery
}

\author{
Kunal P. Raygor, MD, ${ }^{1}$ Doris D. Wang, MD, PhD, ${ }^{1}$ Mariann M. Ward, NP, MS, ${ }^{1}$ \\ Nicholas M. Barbaro, MD, ${ }^{2}$ and Edward F. Chang, MD' \\ 'Department of Neurological Surgery, University of California, San Francisco, California; and 'Department of Neurological \\ Surgery, Indiana University, Indianapolis, Indiana
}

\begin{abstract}
OBJECTIVE Microvascular decompression (MVD) and stereotactic radiosurgery (SRS) are common surgical treatments for trigeminal neuralgia (TN). Many patients who receive SRS have pain recurrence; the ideal second intervention is unknown. The authors directly compared pain outcomes after MVD and repeat SRS in a population of patients in whom SRS failed as their first-line procedure for TN, and they identified predictors of pain control.

METHODS The authors reviewed a prospectively collected database of patients undergoing surgery for TN between 1997 and 2014 at the University of California, San Francisco (UCSF). Standardized data collection focused on preoperative clinical characteristics, surgical characteristics, and postoperative outcomes. Patients with typical type 1, idiopathic $\mathrm{TN}$ with $\geq 1$ year of follow-up were included.

RESULTS In total, 168 patients underwent SRS as their first procedure. Of these patients, 90 had residual or recurrent pain. Thirty of these patients underwent a second procedure at UCSF and had $\geq 1$ year of follow-up; 15 underwent firsttime MVD and 15 underwent repeat SRS. Patients undergoing MVD were younger than those receiving repeat SRS and were more likely to receive $\geq 80$ Gy during the initial SRS. The average follow-up was $44.9 \pm 33.6$ months for MVD and $48.3 \pm 45.3$ months for SRS. All patients achieved complete pain freedom without medication at some point during their follow-up. At last follow-up, $80 \%$ of MVD-treated patients and 33.3\% of SRS-treated patients had a favorable outcome, defined as Barrow Neurological Institute Pain Intensity scores of I-IIIa $(p<0.05)$. Percentages of patients with favorable outcome at 1 and 5 years were $86 \%$ and $75 \%$ for the MVD cohort and $73 \%$ and $27 \%$ for the SRS cohort, respectively ( $p$ $<0.05$ ). Multivariate Cox proportional hazards analysis demonstrated that performing MVD was statistically significantly associated with favorable outcome (HR 0.12, 95\% Cl 0.02-0.60, $p<0.01)$. There were no statistically significant predictors of favorable outcome in the MVD cohort; however, the presence of sensory changes after repeat SRS was associated with pain relief $(p<0.01)$.

CONCLUSIONS Patients who received MVD after failed SRS had a longer duration of favorable outcome compared to those who received repeat SRS; however, both modalities are safe and effective. The presence of post-SRS sensory changes was predictive of a favorable pain outcome in the SRS cohort.
\end{abstract}

https://thejns.org/doi/abs/10.3171/2018.5.JNS172243

KEYWORDS trigeminal neuralgia; microvascular decompression; stereotactic radiosurgery; long-term pain relief; second procedure

$\mathrm{T}$ RIGEMINAL neuralgia (TN) is a facial pain syndrome characterized by sharp, lancinating pain in any of the trigeminal nerve distributions. Microvascular decompression (MVD) and stereotactic radiosurgery (SRS) are among the most commonly performed surgical treatments for TN.
A large body of literature exists describing the efficacy and safety of MVD and SRS for TN; however, significant heterogeneity in patient population and pain type has complicated the interpretation of many studies. First-time and repeat procedures are often included in the same study, and some include patients with atypical pain, especially

ABBREVIATIONS BNI = Barrow Neurological Institute; FIESTA = fast imaging employing steady-state acquisition; MVD = microvascular decompression; SRS = stereotactic radiosurgery; TN = trigeminal neuralgia; UCSF = University of California, San Francisco.

SUBMITTED September 12, 2017. ACCEPTED May 2, 2018.

INCLUDE WHEN CITING Published online October 26, 2018; DOI: 10.3171/2018.5.JNS172243. 
before the classification for TN was introduced. ${ }^{6}$ In addition, very few studies directly compare outcomes after MVD and SRS, and fewer still use prospectively collected data.

We previously reported our institution's longitudinal experience with MVD and SRS as first-line surgical therapies for medically refractory idiopathic $\mathrm{TN} ;{ }^{37}$ however, many patients require a second procedure after initial treatment failure. Pain recurrence rates after initial SRS vary across the literature but range from $40 \%$ to $60 \%$ over 3-5 years. 18,22,27,29,30,37 Though previous studies have reported the efficacy of repeat SRS in patients in whom initial SRS has failed, to our knowledge, this is the first comparison of first-time MVD and repeat SRS as the second surgical intervention for residual or recurrent pain after failed first-time SRS. Additionally, we sought to understand the factors that predict favorable outcome after MVD or repeat SRS. Our study hopes to guide clinical decision-making for patients who have continued TN pain after SRS as their index surgical procedure.

\section{Methods \\ Patient Selection}

As we reported previously, data from all patients undergoing surgical evaluation for TN at the University of California, San Francisco (UCSF), was prospectively collected starting in $1997 .{ }^{37}$ The data in this study include those obtained from patients evaluated between 1997 and 2014. Patients were included only if they met the following inclusion criteria: no evidence of mass lesions compressing the trigeminal nerve, no multiple sclerosis, and had classic type 1 TN pain symptoms. Patients with $>50 \%$ constant pain (type $2 \mathrm{TN}$ ), those with injury to the trigeminal nerve (neuropathic or deafferentation pain), those with postherpetic neuralgia, and those with atypical facial pain in the setting of somatoform pain disorder were excluded from the analysis. ${ }^{6}$ Patients with $<1$ year of follow-up were also excluded from this analysis. In total, 168 patients who met inclusion criteria underwent SRS as the first procedure for medically refractory, idiopathic type $1 \mathrm{TN}$. Of those, 40 had residual symptoms and 50 developed recurrent symptoms after achieving initial pain freedom. Briefly, residual or recurrent symptoms are defined as having a Barrow Neurological Institute (BNI) Pain Intensity score of IIIb$\mathrm{V}$ at last follow-up. Thirty of the 90 patients in whom firsttime SRS failed returned to our institution for a second procedure -15 underwent MVD and 15 underwent repeat SRS - and had at least 1 year of follow-up after this second procedure. All procedures were performed by either N.M.B. or E.F.C. The decision to perform MVD or repeat SRS was based on the patient's request after a discussion of the perceived risks and benefits specific to each patient. This included considerations of the patient's medical comorbidities, any evidence of vascular compression shown on MRI, and patient preference. All research protocols were approved by the UCSF Institutional Review Board (Committee for Human Research).

\section{Data Collection}

Data were collected both pre- and postoperatively in a systematic fashion. At the initial clinic visit, patient demographics, symptom duration, symptom location, symptom features, relevant family and medical history, baseline physical examination findings, and imaging findings were recorded. Postoperative clinic visits were routinely scheduled at $1,3,6$, and 12 months, and additional visits were scheduled as needed. Phone interviews were conducted to obtain additional follow-up information. Symptom features, medications used, sensory disturbances, and postoperative physical examination findings were recorded. If a patient missed follow-up appointments, information (excluding physical examination findings) was collected via telephone encounters.

\section{Outcome Measures}

The primary outcome was BNI Pain Intensity score at last follow-up. The BNI score exists on a scale of I-V as follows: score I, no pain with no medication; score II, occasional pain with no medication; score IIIa, no pain on medication; score IIIb, some pain controlled with medication; score IV, some pain not controlled with medication; and score V, severe pain without relief. ${ }^{31}$ Surgical complications and postoperative sensory changes were recorded as sensory outcomes. Patients were deemed to be pain free if they had no TN pain and were off medications (BNI score I). Patients were deemed to have a favorable outcome if they had BNI scores I-IIIa at last follow-up and had an unfavorable outcome if they had a BNI score of IIIb-V at last follow-up. There were no patients with a score of IIIa in this cohort of patients in whom initial SRS failed.

\section{Procedural Technique Initial SRS}

SRS was performed using a Gamma Knife apparatus. The Leksell stereotactic head frame (Elekta Instruments, $\mathrm{AB}$ ) was applied after the patients were given a local anesthetic and patients underwent stereotactic MRI. Highresolution T2-weighted images or T2-type fast imaging employing steady-state acquisition (FIESTA) sequences and contrast-enhanced T1-weighted images were used for target planning. The cisternal portion of the trigeminal nerve was targeted with a single isocenter using a 4-mm collimator. Doses for initial SRS ranged from 60 to 85 Gy. Thirteen of 15 patients (86.7\%) in the MVD cohort received $80 \mathrm{~Gy}$, with 1 each receiving 60 and $85 \mathrm{~Gy}$. Eight of 15 patients (53.3\%) in the SRS cohort received 80 Gy, with 5 receiving 75 Gy and 2 receiving 70 Gy.

\section{MVD}

MVD was performed following previously described techniques. ${ }^{5,16,23}$ Briefly, after making a small retrosigmoid craniectomy, the trigeminal nerve was examined for vascular compression at the root entry zone or along its cisternal portion. Compressive arteries or veins were dissected away from the nerve, padded with Teflon felt, and secured with biological adhesive. In 5 cases (33.3\%) in which no significant intraoperative vascular compression was visualized, a partial sensory rhizotomy was performed. Intraoperative auditory brainstem evoked potential monitoring was used on all patients. 


\section{Repeat SRS}

Repeat SRS was performed using the same techniques as initial SRS, except in some cases two isocenters were used. In those cases, one isocenter targeted the cisternal portion of the nerve with shielding from the second isocenter. Doses for repeat SRS ranged from 40 to $80 \mathrm{~Gy}$. Eight patients (53.3\%) received 50 Gy, with 2 receiving 40 Gy, and 1 each receiving 45, 55, 60, 70, and $80 \mathrm{~Gy}$.

\section{Postoperative Medication Management}

Patients' primary care physicians and neurologists outside the UCSF health system assisted in titration of TN medication postoperatively; therefore, tapers were not standardized. Patients undergoing MVD were typically advised to start weaning their medication 2-6 weeks after becoming pain free, whereas those undergoing SRS were advised to start weaning medications 6 weeks after achieving pain control.

\section{Statistical Analysis}

All statistical analyses were performed using JMP Pro version 13.0.0 (SAS Institute Inc.). Continuous predictor and outcome variables were compared using a 2-tailed Student t-test or the Mann-Whitney U-test, as appropriate. Categorical variables were compared with Fisher's exact test. Pain-free duration was plotted using Kaplan-Meier survival analysis, and statistical significance was measured with the log-rank test. Multivariate Cox proportional hazards modeling was used to determine the effect of multiple variables on time to pain recurrence. Only variables with $\mathrm{p}<0.2$ from univariate analysis were used in the multivariate regression model to avoid overfitting. The threshold for significance was set at $\mathrm{p}=0.05$.

\section{Results}

Between 1997 and 2015, 168 patients underwent SRS as their initial surgical therapy for medically refractory, idiopathic, type $1 \mathrm{TN}$ and had at least 1 year of follow-up. Ninety patients had an unfavorable outcome (BNI score III-V) at last follow-up. Of those patients, 30 underwent a second procedure at UCSF and had $>1$ year of followup. Kaplan-Meier survival analysis depicts the time until pain recurrence after initial SRS for these 30 patients (Fig. 1). The median pain-free duration was 13.9 months (IQR 4.1-52.0). The estimated percentages of patients with a favorable outcome after initial SRS were $50 \%$ at 1 year and $20 \%$ at 5 years. Half of the patients $(n=15)$ underwent first-time MVD as a second procedure, and the remainder underwent repeat SRS. Demographic data for these two cohorts are shown in Table 1. Patients who underwent first-time MVD as the second procedure were younger at the time of their second procedure than those receiving a second-time SRS (mean age 63.3 years vs 75.8 years; $\mathrm{p}=$ 0.04). Those who underwent MVD were also more likely to receive an initial SRS dose of $\geq 80$ Gy than those who underwent repeat SRS $(93.3 \%$ vs $53.3 \%$; $\mathrm{p}=0.04)$. The median initial SRS dose was 80 Gy (IQR 80-80) in the MVD cohort and 80 Gy (IQR 75-80) in the repeat SRS cohort. There were no statistically significant differences in sex, laterality or distribution of pain, family history,

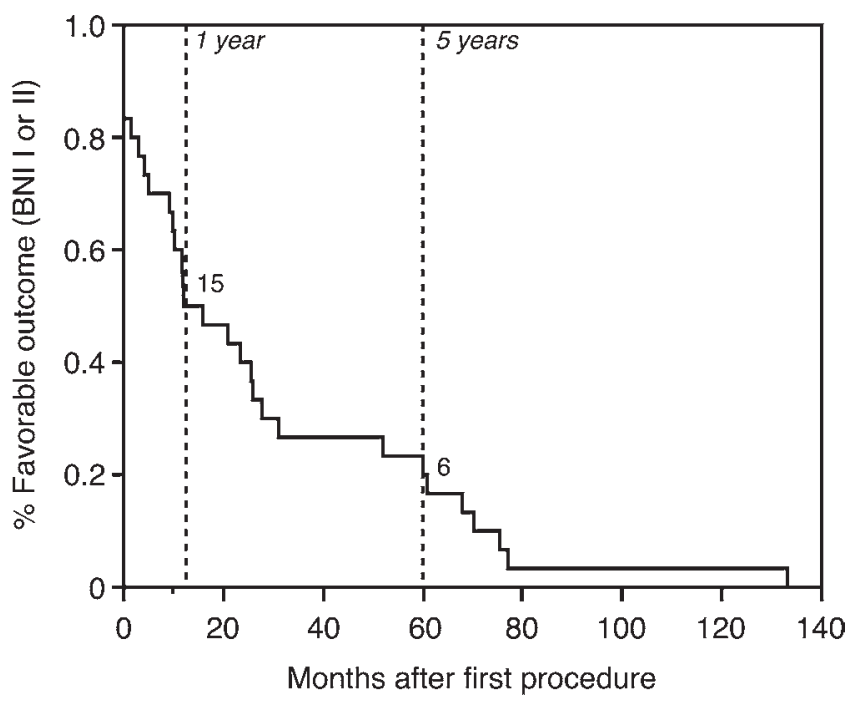

FIG. 1. Pain recurrence after initial SRS for all 30 patients. A KaplanMeier survival curve for the entire patient population is shown. Values in the graph represent the number of patients from each group reaching time points indicated by the vertical dashed lines.

symptom duration, age at the time of initial SRS, or time until pain recurrence after initial SRS. Though 2 patients in each cohort had temporary sensory changes after initial SRS, no patients reported numbness, dysesthesias, or anesthesia dolorosa at the time of their second procedure. In addition, though there was a trend for patients in the MVD cohort to have trigeminal nerve compression seen on preoperative MRI compared to those in the SRS cohort, this was not statistically significant $(60 \%$ vs $27 \%, \mathrm{p}=0.06)$. The mean follow-up duration after the second procedure was 44.9 months in the MVD cohort and 48.3 months in the SRS cohort $(p=0.09)$.

\section{Pain Outcomes After MVD or SRS}

Patients who underwent MVD as a second-line treatment had a longer pain-free duration than patients who underwent repeat SRS. All patients achieved pain-free status (BNI score I) at some point following their procedure, although the MVD cohort achieved this control faster (4.6 weeks vs 20.1 weeks for the SRS group, $p=0.05$ ). At last follow-up, 9 patients in the MVD cohort (60\%) and 3 in the SRS cohort (20\%) were pain free and off medications (BNI score I). Similarly, 12 MVD patients (80\%) and 5 SRS patients $(33.3 \%$ ) had favorable outcomes at last follow-up $(\mathrm{p}=0.03)$. One patient in each group $(6.7 \%$ each) had some pain adequately controlled with medication (BNI score IIIb), and 2 patients in the MVD group (13.3\%) and 9 in the SRS group (80\%) had severe pain without any relief after the second procedure (BNI score $\mathrm{V})$. There were no statistically significant differences in the presence of postoperative sensory changes or adverse event rates between the two cohorts. In addition, there were no cases of painful dysesthesias or anesthesia dolorosa after the second procedure in either cohort. Two adverse events occurred in the MVD group: one patient developed a CSF leak requiring diversion via placement 
TABLE 1. Demographic data and clinical characteristics of patients in the MVD and repeat SRS cohorts

\begin{tabular}{|c|c|c|c|}
\hline Characteristic & MVD & $\begin{array}{l}\text { Repeat } \\
\text { SRS }\end{array}$ & $\begin{array}{c}p \\
\text { Value }\end{array}$ \\
\hline No. of patients & 15 & 15 & \\
\hline Male sex & $8(53.3 \%)$ & $6(40 \%)$ & 0.72 \\
\hline TN laterality & & & 0.43 \\
\hline Right & $9(60 \%)$ & $12(80 \%)$ & \\
\hline Left & $6(40 \%)$ & $3(20 \%)$ & \\
\hline TN distribution & & & 0.14 \\
\hline$V_{1}$ & $3(20 \%)$ & $4(26.7 \%)$ & \\
\hline$V_{2}$ & $0(0 \%)$ & $2(13.3 \%)$ & \\
\hline$V_{3}$ & $5(33.3 \%)$ & $7(46.7 \%)$ & \\
\hline$V_{1}+V_{2}$ & $0(0 \%)$ & $1(6.7 \%)$ & \\
\hline$V_{2}+V_{3}$ & $3(20 \%)$ & $1(6.6 \%)$ & \\
\hline$V_{1}-V_{3}$ & $4(26.7 \%)$ & $0(0 \%)$ & \\
\hline Family history & $0(0 \%)$ & $1(6.7 \%)$ & 1.00 \\
\hline Mean age at 1 st SRS in yrs & $60.9 \pm 16.1$ & $71.0 \pm 14.0$ & 0.08 \\
\hline $\begin{array}{l}\text { Mean symptom duration at 1st } \\
\text { SRS in mos }\end{array}$ & $95.9 \pm 66.1$ & $109.0 \pm 87.6$ & 0.65 \\
\hline Dose of 1 st SRS & & & $0.04^{*}$ \\
\hline$\geq 80 \mathrm{~Gy}$ & $14(93.3 \%)$ & $8(53.3 \%)$ & \\
\hline$<80 \mathrm{~Gy}$ & $1(6.7 \%)$ & $7(46.7 \%)$ & \\
\hline Transient pain relief w/ 1st SRS & $13(86.7 \%)$ & $12(80 \%)$ & 1.00 \\
\hline $\begin{array}{l}\text { Transient sensory change w/ 1st } \\
\text { SRS }\end{array}$ & $2(13.3 \%)$ & $2(13.3 \%)$ & 1.00 \\
\hline $\begin{array}{l}\text { Mean time to pain recurrence after } \\
\text { 1st SRS in mos }\end{array}$ & $17.9 \pm 18.7$ & $38.4 \pm 39.7$ & 0.09 \\
\hline Preprocedure sensory disturbance & $0(0 \%)$ & $0(0 \%)$ & 1.00 \\
\hline Mean age at 2 nd procedure in yrs & $63.3 \pm 17.0$ & $75.8 \pm 13.9$ & $0.04^{*}$ \\
\hline $\begin{array}{l}\text { Vascular compression on preop } \\
\text { MRI }\end{array}$ & $9(60 \%)$ & $4(26.7 \%)$ & 0.06 \\
\hline Mean FU in mos & $44.9 \pm 33.6$ & $48.3 \pm 45.3$ & 0.09 \\
\hline
\end{tabular}

$\mathrm{FU}=$ follow-up.

Values are presented as the number (\%) of patients unless otherwise noted. Mean values are presented \pm SD.

* Denotes statistical significance.

of a lumbar subarachnoid drain followed by wound revision, and the other patient developed unilateral hyperacusis, presumably due to intraoperative injury to the acoustic portion of cranial nerve VIII. These outcomes are summarized in Table 2.

Kaplan-Meier survival analysis was performed to further analyze the difference in pain-free outcomes over time between the two groups. Survival functions depicting time to pain recurrence showed divergent outcomes for the MVD and SRS cohorts. The median duration of favorable outcome was not reached in the MVD group but was 30 months in the SRS group $(p=0.03)$ (Table 2). Percentages of patients with a favorable outcome at 1 and 5 years were $86 \%$ and $75 \%$ for the MVD cohort compared to $73 \%$ and $27 \%$ for the SRS cohort, respectively (Fig. 2). Multivariate Cox regression modeling was performed to determine if any other variables could predict pain-free duration. Undergoing MVD as the second procedure was
TABLE 2. Pain relief outcomes among patients in the MVD and repeat SRS cohorts

\begin{tabular}{lccc}
\hline \multicolumn{1}{c}{ Outcome } & MVD & Repeat SRS & p Value \\
\hline No. of patients & 15 & 15 & \\
\hline Ever pain free (BNI score I) & $15(100 \%)$ & $15(100 \%)$ & 1.00 \\
\hline $\begin{array}{l}\text { Median time to BNI score I } \\
\text { in wks (range) }\end{array}$ & $0(0-56.4)$ & $9.9(2.3-104.9)$ & $0.001^{*}$ \\
\hline $\begin{array}{l}\text { BNI Pain Intensity score at } \\
\text { last FU }\end{array}$ & & & $0.04^{*}$ \\
I & $9(60 \%)$ & $3(20 \%)$ & \\
II & $3(20 \%)$ & $2(13.3 \%)$ & \\
IIla & $0(0 \%)$ & $0(0 \%)$ & \\
IIIb & $1(6.7 \%)$ & $1(6.7 \%)$ & \\
IV & $0(0 \%)$ & $0(0 \%)$ & \\
V & $2(13.3 \%)$ & $9(80 \%)$ & \\
\hline $\begin{array}{l}\text { Favorable outcome at last } \\
\text { FU (BNI score I-IIla) }\end{array}$ & $12(80 \%)$ & $5(33.3 \%)$ & $0.03^{*}$ \\
\hline Median pain-free duration & $-(-,) \dagger$ & $30.0(7.6, \ldots) \dagger$ & $0.03^{*}$ \\
in mos (IQR) & $4(26.7 \%)$ & $6(40 \%)$ & 0.70 \\
\hline Postop sensory change & $2(13.3 \%)$ & $0(0 \%)$ & 0.48 \\
\hline Complications
\end{tabular}

Values are presented as the number (\%) of patients unless otherwise noted. * Denotes statistical significance.

† These numbers/characters reflect the time it takes for $50 \%$ of patients to have pain recurrence after the respective procedure (median), or for $25 \%$ or $75 \%$ of patients to have pain recurrence (reflected in the IQR). The MVD cohort never reaches $25 \%$ failure so all three components cannot be calculated (" "). The SRS cohort has $>50 \%$ but $<75 \%$ of patients fail so there is a $25 \%$ value and median value (50\%) but nothing for the $75 \%$ value (upper component of the IQR).

the only statistically significant predictor of favorable outcome (HR 0.12, 95\% CI 0.02-0.60; p = 0.008) (Table $3)$. Pain distribution, age at first or second procedure, radiation dose at initial SRS, time to pain recurrence after initial SRS, and time to pain freedom after second procedure were not statistically significant in this multivariate model.

\section{Predictors of Favorable Outcome After MVD}

Compression-related characteristics and results of univariate analyses of pain freedom after MVD are reported in Table 4; there were no statistically significant predictors of favorable outcome. Despite the fact that only $60 \%$ of MVD patients had MRI evidence of vascular compression on the nerve, intraoperative visualization of compression was seen in $92 \%$ of cases. There was a trend for MVD patients with favorable outcome to have arterial compression on the nerve, although this was not statistically significant $(\mathrm{p}=0.07)$. Of those patients with evidence of arterial compression, the culprit artery was the superior cerebellar artery in 9 of the 10 cases; the remaining patient had a loop of the anterior inferior cerebellar artery that caused compression. One patient with superior cerebellar artery compression also had dense adhesions around the nerve; in this patient, it was still possible to perform MVD safely. One-third of the patients in the MVD cohort underwent a partial sensory rhizotomy intraoperatively; 


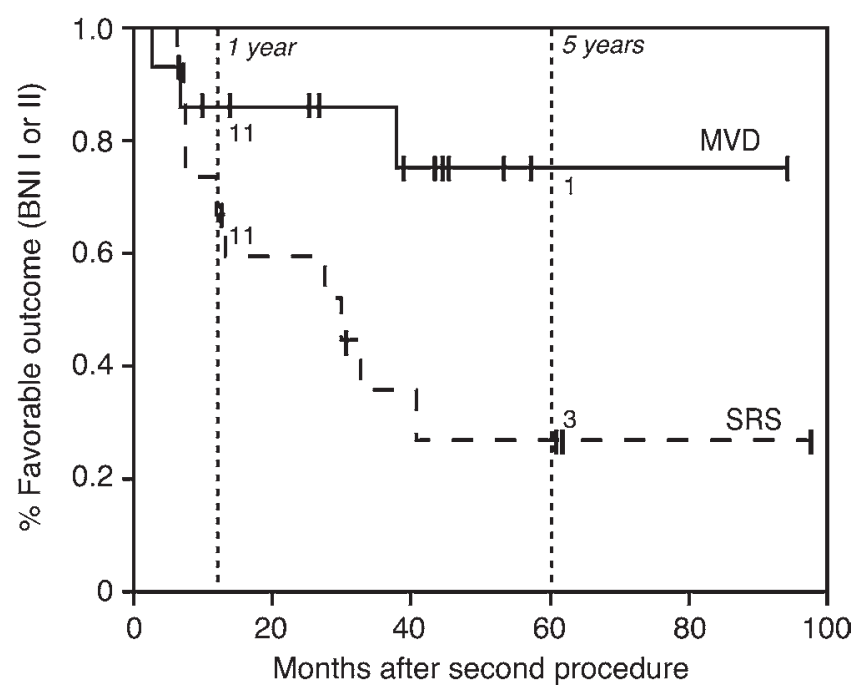

FIG. 2. Pain recurrence by procedure type: MVD versus repeat SRS. Kaplan-Meier survival curves for each cohort are shown, with tick marks representing censored events. Values in the graph represent the number of patients from each group reaching time points indicated by the vertical dashed lines.

3 had a favorable outcome and 2 had an unfavorable outcome $(\mathrm{p}=0.24)$.

\section{Predictors of Favorable Outcome After SRS}

Fifteen patients underwent SRS, and the cumulative SRS dose from the first and second Gamma Knife procedures varied. One patient each received a cumulative radiation dose of 155,150 , and $140 \mathrm{~Gy}$ (6.7\% each); 6 patients $(40 \%)$ received 130 Gy; $2(13.5 \%)$ received 125 Gy; $3(20 \%)$ received $120 \mathrm{~Gy}$; and $1(6.7 \%)$ received $110 \mathrm{~Gy}$. There was no significant difference in cumulative SRS dose between those patients with favorable and unfavorable outcomes $(p=0.71)$. In addition, the median time to a pain-free outcome was 14.2 weeks in patients in whom a favorable outcome was achieved, whereas it was 23.1 weeks in those with an unfavorable outcome at the last follow-up $(p=0.43)$. Post-SRS sensory changes occurred in 6 of the 15 patients in the SRS cohort; of these, 5 (83\%) had a favorable outcome and $1(17 \%)$ had an unfavorable outcome $(\mathrm{p}=0.002)$. No patient developed painful or bothersome dysesthesias. There were no statistically significant associations between favorable outcome and any of the other predictor variables: sex, TN laterality, TN distribution, age at first or second SRS procedure, dose of first SRS, presence of transient pain relief after first SRS, presence of transient sensory change after first SRS, time to pain recurrence after first SRS, and number of isocenters used during the second SRS procedure (Table 5). The median duration of a favorable outcome in patients who did not have post-SRS hypesthesia (defined as decreased sensitivity to touch) was 13 months (IQR 7.6-30), whereas no median pain-free duration was reached in the cohort with sensory changes $(p=0.01)$. Rates of favorable outcome were $83 \%$ at 1 and 5 years for those with post-SRS sensory changes compared to $55 \%$
TABLE 3. Multivariate Cox proportional hazard analysis of favorable outcome

\begin{tabular}{lll}
\hline \multicolumn{1}{c}{ Predictor Variable } & \multicolumn{1}{c}{$\begin{array}{c}\text { Hazard Ratio } \\
(95 \% \mathrm{Cl})\end{array}$} & $\begin{array}{c}\mathrm{p} \\
\text { Value }\end{array}$ \\
\hline Undergoing MVD as 2nd procedure & $0.12(0.02-0.60)$ & $0.008^{*}$ \\
\hline Dose $\geq 80$ Gy at 1st SRS & $0.57(0.06-4.81)$ & 0.60 \\
\hline TN distribution & & 0.28 \\
$V_{1}$ vs $\mathrm{V}_{1}-\mathrm{V}_{3}$ & $0.49(0.03-8.23)$ & \\
$\mathrm{V}_{2}$ vs $\mathrm{V}_{1}-\mathrm{V}_{3}$ & $0.02(0.00-2.46)$ & \\
$\mathrm{V}_{3}$ vs $\mathrm{V}_{1}-\mathrm{V}_{3}$ & $0.23(0.01-3.97)$ & \\
$\mathrm{V}_{1}+\mathrm{V}_{2}$ vs $\mathrm{V}_{1}-\mathrm{V}_{3}$ & $0(0-0)$ & \\
$\mathrm{V}_{2}+\mathrm{V}_{3}$ vs $\mathrm{V}_{1}-\mathrm{V}_{3}$ & $0.56(0.03-11.79)$ & \\
\hline Age at st SRS & $1.54(0.72-3.63)$ & 0.26 \\
\hline Time to pain recurrence after 1st SRS & $1.03(0.98-1.10)$ & 0.22 \\
\hline Age at 2nd procedure & $0.65(0.27-1.38)$ & 0.27 \\
\hline Time to BNI score I after 2nd procedure & $1.03(0.99-1.07)$ & 0.15 \\
\hline
\end{tabular}

* Denotes statistical significance.

and $0 \%$ at 1 and 5 years, respectively, for those without sensory change (Fig. 3).

\section{Discussion}

Our study sought to determine the comparative effectiveness of repeat SRS and first-time MVD as the second overall procedure for idiopathic, type $1 \mathrm{TN}$ in patients in whom an initial SRS procedure failed. While MVD has been shown to create long periods of pain freedom, $3,7,21,34,37$ no prior study, to our knowledge, has directly studied the ideal treatment strategy for recurrence after initial SRS. Prior work has shown that radiosurgery alters trigeminal nerve histopathology and that persistent histological changes are likely needed for the effect of radiosurgery to persist. ${ }^{1,11,17}$ Brainstem and trigeminal nerve enhancement is seen after SRS and is associated with pain relief; ${ }^{12}$ however, this enhancement takes time to evolve (approximately the median time to pain relief) and is thus not sufficient in and of itself to predict pain freedom. In addition, diffusion tensor imaging tractography in patients who have completed focal radiosurgery demonstrates reduced fractional anisotropy and increased radial diffusivity, suggesting focal changes in myelination after SRS. ${ }^{14}$ Despite these microstructural changes to the nerve, patients who receive initial SRS often have residual or recurrent pain. As such, it is unknown if the pathophysiology of TN before treatment is the same as the pathophysiology after initial SRS; similarly, there is reason to believe that the trigeminal nerve has changed after initial SRS, and it is possible that repeat SRS may not be as effective as initial SRS. For this reason, we believe data comparing pain relief outcomes after MVD and repeat SRS are necessary to make clinical decisions in individuals with refractory pain after first-time SRS.

In our cohort of 30 patients who had residual or recurrent pain after first-line SRS for medically refractory TN, MVD led to a significantly longer pain-free period than repeat SRS. The decision to perform MVD as opposed to SRS was not directly influenced by the presence of vas- 
TABLE 4. Univariate analysis of MVD outcomes

\begin{tabular}{|c|c|c|c|c|}
\hline Variable & Total & Favorable (BNI score I or II) & Unfavorable (BNI score III-V) & $\mathrm{p}$ Value \\
\hline No. of patients & 15 & 12 & 3 & \\
\hline Male sex & $8(53 \%)$ & $8(100 \%)$ & $0(0 \%)$ & 0.08 \\
\hline TN laterality & & & & 1.00 \\
\hline Right & $9(60 \%)$ & $7(77.8 \%)$ & $2(22.2 \%)$ & \\
\hline Left & $6(40 \%)$ & $5(83.3 \%)$ & $1(16.7 \%)$ & \\
\hline TN distribution & & & & 1.00 \\
\hline$V_{1}$ & $3(20 \%)$ & $3(100 \%)$ & $0(0 \%)$ & \\
\hline $\mathrm{V}_{2}$ & $0(0 \%)$ & $0(0 \%)$ & $0(0 \%)$ & \\
\hline $\mathrm{V}_{3}$ & $5(33.3 \%)$ & $4(80 \%)$ & $1(20 \%)$ & \\
\hline$V_{1}+V_{2}$ & $0(0 \%)$ & $0(0 \%)$ & $0(0 \%)$ & \\
\hline$V_{2}+V_{3}$ & $3(20 \%)$ & $2(66.7 \%)$ & $1(13.3 \%)$ & \\
\hline$V_{1}-V_{3}$ & $4(26.7 \%)$ & $3(75 \%)$ & $1(25 \%)$ & \\
\hline Mean age at 1 st $S R S$ in yrs, \pm SD & $60.9 \pm 16.1$ & $60.1 \pm 17.5$ & $64.0 \pm 10.8$ & 0.64 \\
\hline Symptom duration at 1 st SRS in mos, \pm SD & $95.9 \pm 66.1$ & $89.4 \pm 64.3$ & $122.0 \pm 81.0$ & 0.57 \\
\hline Dose of 1st SRS & & & & 1.00 \\
\hline$\geq 80$ Gy & $14(93.3 \%)$ & $11(78.6 \%)$ & $3(21.4 \%)$ & \\
\hline$<80 \mathrm{~Gy}$ & $1(6.7 \%)$ & $1(100 \%)$ & $0(0 \%)$ & \\
\hline Transient pain relief $w / 1$ st SRS & $13(86.7 \%)$ & $10(76.9 \%)$ & $3(23.1 \%)$ & 1.00 \\
\hline Transient sensory change w/ 1st SRS & $2(13.3 \%)$ & $2(100 \%)$ & $0(0 \%)$ & 1.00 \\
\hline Mean time to pain recurrence after 1 st SRS in mos, \pm SD & $17.9 \pm 18.7$ & $17.9 \pm 20.2$ & $18.3 \pm 14.2$ & 0.97 \\
\hline Mean age at 2 nd procedure in yrs, \pm SD & $63.3 \pm 17.0$ & $62.6 \pm 18.6$ & $66.0 \pm 9.7$ & 0.68 \\
\hline Mean time to pain free in wks, \pm SEM & $4.6 \pm 3.8$ & $4.7 \pm 4.7$ & $4.2 \pm 2.5$ & 0.93 \\
\hline Rhizotomy performed & $5(33.3 \%)$ & $3(60 \%)$ & $2(40 \%)$ & 0.24 \\
\hline MRI compression & $9(60 \%)$ & $8(88.9 \%)$ & $1(11.1 \%)$ & 0.53 \\
\hline Intraop compression & $14(91.7 \%)$ & $11(78.6 \%)$ & $3(21.4 \%)$ & 1.00 \\
\hline Compressing vessel & & & & 0.07 \\
\hline Artery only & $10(66.7 \%)$ & $9(90 \%)$ & $1(10 \%)$ & \\
\hline Vein only & $2(13.3 \%)$ & $0(0 \%)$ & $2(100 \%)$ & \\
\hline Artery + vein & $2(13.3 \%)$ & $2(100 \%)$ & $0(0 \%)$ & \\
\hline None & $1(6.7 \%)$ & $1(100 \%)$ & $0(0 \%)$ & \\
\hline Sensory change post-MVD & $4(26.7 \%)$ & $4(100 \%)$ & $0(0 \%)$ & 0.52 \\
\hline
\end{tabular}

Values are presented as the number of patients (\%) unless otherwise noted. Mean values are presented \pm SD or \pm SEM, as noted.

cular compression on preoperative MRI; there was no statistically significant difference in rates of MRI evidence of compression in the two cohorts. Compared to our previously published analysis of all patients who underwent SRS as their first-line procedure, patients who underwent repeat SRS had a lower median duration of favorable outcome (53 months for initial SRS vs 30 months for repeat SRS). ${ }^{37}$ Despite differences in patient demographics, including radiation dose at the time of initial SRS, TN distribution, age, and time to pain recurrence after initial SRS, only MVD was a statistically significant predictor of pain relief in the multivariate analysis.

The decision to perform MVD rather than repeat SRS is of particular importance for elderly patients who are more likely to have limiting medical comorbidities. Although MVD can be safe and effective in the elderly, ${ }^{33}$ those patients who cannot tolerate general anesthesia should still consider ablative procedures, including radiofrequency lesionectomy and SRS, since SRS in particular has been shown to be very effective in patients older than 70 years of age. ${ }^{9}$ In addition, patients receiving SRS avoid the risk of postoperative adverse events: Complications of MVD include CSF leak, meningitis, wound infection, facial paralysis, hearing loss, hematoma, and death. ${ }^{4}$ In our study, one MVD patient developed a CSF leak requiring return to the operating room and another MVD patient developed postoperative hyperacusis; no patient who underwent SRS had an adverse event.

\section{Favorable Outcomes After MVD}

Univariate analysis in our study failed to uncover any specific predictors of pain freedom in the cohort of patients receiving first-time MVD after failed SRS. Prior reports have suggested that immediate pain relief, male sex, arterial compression, and shorter preoperative symptom duration are predictive of pain freedom after MVD. . $^{3,24,25,32,36,37}$ Preoperative MRI demonstrating vascular compression of the trigeminal nerve was present in $66.6 \%$ of patients with a favorable outcome and $33.3 \%$ of patients with an unfavorable outcome, although this was not statistically significant in our population. This may be due to the small sample size of the study and to the fact that fast spin echo sequences 
TABLE 5. Univariate analysis of repeat SRS outcomes

\begin{tabular}{|c|c|c|c|c|}
\hline Variable & Total & Favorable (BNI score I or II) & Unfavorable (BNI score III-V) & $p$ Value \\
\hline No. of patients & 15 & 5 & 10 & - \\
\hline Male sex & $6(40 \%)$ & $1(16.7 \%)$ & $5(83.3 \%)$ & 0.58 \\
\hline TN laterality & & & & 0.51 \\
\hline Right & $12(80 \%)$ & $5(41.7 \%)$ & $7(58.3 \%)$ & \\
\hline Left & $3(20 \%)$ & $0(0 \%)$ & $3(100 \%)$ & \\
\hline TN distribution & & & & 0.28 \\
\hline$V_{1}$ & $4(26.7 \%)$ & $0(0 \%)$ & $4(100 \%)$ & \\
\hline$V_{2}$ & $2(13.3 \%)$ & $1(50 \%)$ & $1(50 \%)$ & \\
\hline $\mathrm{V}_{3}$ & $7(46.7 \%)$ & $3(42.9 \%)$ & $4(57.1 \%)$ & \\
\hline$V_{1}+V_{2}$ & $1(6.7 \%)$ & $1(100 \%)$ & $0(0 \%)$ & \\
\hline$V_{2}+V_{3}$ & $1(6.6 \%)$ & $0(0 \%)$ & $1(100 \%)$ & \\
\hline$V_{1}-V_{3}$ & $0(0 \%)$ & $0(0 \%)$ & $0(0 \%)$ & \\
\hline Mean age at 1 st $S R S$ in yrs, \pm SD & $71.0 \pm 14.0$ & $72.6 \pm 12.9$ & $70.2 \pm 15.1$ & 0.76 \\
\hline Mean symptom duration at 1 st SRS in mos, \pm SD & $109.0 \pm 87.6$ & $82.4 \pm 57.6$ & $122.3 \pm 99.4$ & 0.34 \\
\hline Dose of 1 st SRS & & & & 0.61 \\
\hline$\geq 80 \mathrm{~Gy}$ & $8(53.3 \%)$ & $2(25 \%)$ & $6(75 \%)$ & \\
\hline$<80$ Gy & $7(46.7 \%)$ & $3(42.9 \%)$ & $4(57.1 \%)$ & \\
\hline Transient pain relief w/ 1st SRS & $12(80 \%)$ & $4(33.3 \%)$ & $8(66.7 \%)$ & 1.00 \\
\hline Transient sensory change w/ 1st SRS & $2(13.3 \%)$ & $1(50 \%)$ & $1(50 \%)$ & 1.00 \\
\hline Mean time to pain recurrence after 1 st SRS in mos, \pm SD & $38.4 \pm 39.7$ & $45.8 \pm 31.9$ & $34.7 \pm 44.3$ & 0.59 \\
\hline Mean age at 2 nd procedure in yrs, \pm SD & $75.8 \pm 13.9$ & $77.7 \pm 12.5$ & $74.8 \pm 15.1$ & 0.70 \\
\hline Cumulative SRS dose & & & & 0.71 \\
\hline $155 \mathrm{~Gy}$ & $1(6.7 \%)$ & $0(0 \%)$ & $1(100 \%)$ & \\
\hline $150 \mathrm{~Gy}$ & $1(6.7 \%)$ & $0(0 \%)$ & $1(100 \%)$ & \\
\hline $140 \mathrm{~Gy}$ & $1(6.7 \%)$ & $0(0 \%)$ & $1(100 \%)$ & \\
\hline $130 \mathrm{~Gy}$ & $6(40 \%)$ & $2(33.3 \%)$ & $4(67.7 \%)$ & \\
\hline 125 Gy & $2(13.2 \%)$ & $2(100 \%)$ & $0(0 \%)$ & \\
\hline $120 \mathrm{~Gy}$ & $3(20 \%)$ & $1(33.3 \%)$ & $2(67.7 \%)$ & \\
\hline 110 Gy & $1(6.7 \%)$ & $0(0 \%)$ & $1(100 \%)$ & \\
\hline No. of isocenters w/ 2nd SRS & & & & 1.00 \\
\hline 1 & $9(60 \%)$ & $3(33.3 \%)$ & $6(67.7 \%)$ & \\
\hline 2 & $6(40 \%)$ & $2(33.3 \%)$ & $4(67.7 \%)$ & \\
\hline Mean time to pain free in wks, \pm SEM & $20.1 \pm 6.6$ & $14.2 \pm 4.8$ & $23.1 \pm 9.7$ & 0.43 \\
\hline Sensory change post-SRS & $6(40 \%)$ & $5(83.3 \%)$ & $1(16.7 \%)$ & $0.002^{*}$ \\
\hline
\end{tabular}

Values are presented as the number of patients (\%) unless otherwise noted. Mean values are presented \pm SD or \pm SEM, as noted.

*Denotes statistical significance.

such as FIESTA (which are the most likely to demonstrate neurovascular contact) were not routinely obtained in the early years of the reporting period. The degree of agreement between imaging and operative findings with respect to neurovascular contact is promising but does vary in the literature, with Cohen's kappa coefficient ranging from 0.75 to $0.92 .^{8,19,20,39}$ In cases in which no vascular compression was seen intraoperatively, a partial sensory rhizotomy was often performed. Our previous work has shown that although rhizotomy can initially lead to pain relief rates comparable to pure MVD alone, the response rates become divergent at 6 months postoperatively. ${ }^{37}$ In our cohort of patients undergoing a second procedure, however, there was no statistically significant association between rhizotomy and a favorable outcome; 3 patients $(60 \%$; $95 \%$ CI 23\%-88\%) undergoing rhizotomy had a favorable outcome compared to 2 (40\%; $95 \%$ CI $12 \%-77 \%)$ who had an unfavorable outcome ( $p=0.24$; Table 4). The discrepancy in outcomes after partial sensory rhizotomy described here may be related to some of the nerve's microstructural changes that occur after initial SRS but may also be confounded by the overall small sample size in this study.

\section{Favorable Outcomes After Repeat SRS}

Our analysis is consistent with multiple prior studies that demonstrate that post-SRS sensory changes predict pain freedom after repeat SRS.26,29 The only statistically significant predictor of favorable outcome after repeat SRS in our cohort was post-SRS sensory change, which occurred in $100 \%$ of patients with a favorable outcome compared to $10 \%$ of patients with an unfavorable outcome. The median time to pain recurrence was not reached in the cohort with sensory change but was 13 months in those who did not develop any sensory change. 


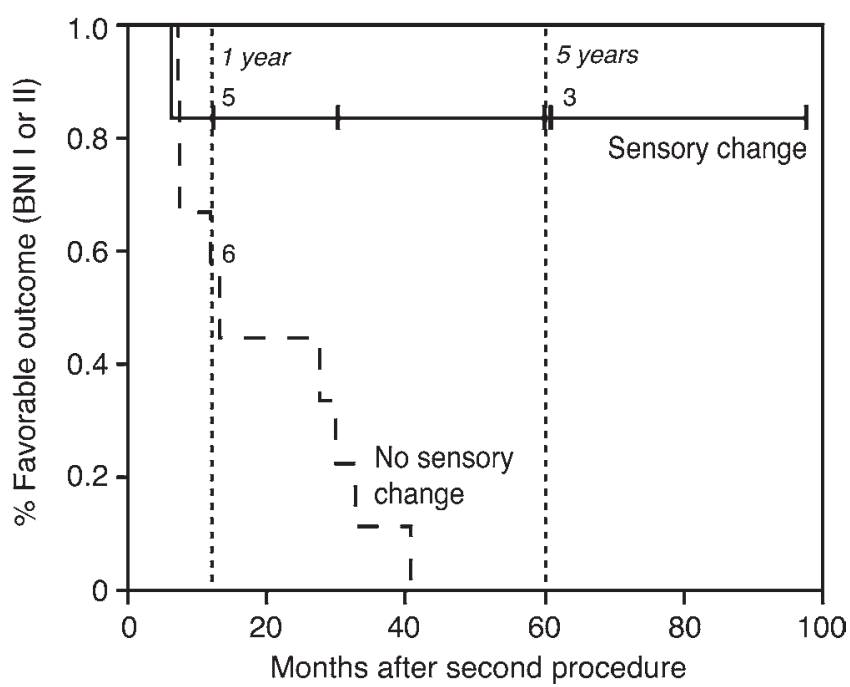

FIG. 3. Pain recurrence among the SRS cohort by the presence of post-SRS sensory changes. Kaplan-Meier survival curves are shown for each subpopulation, with tick marks representing censored events. Values in the graph represent the number of patients from each group reaching time points indicated by the vertical dashed lines.

Importantly, a majority of patients with permanent postSRS hypesthesia have described the pain freedom they experience after repeat radiosurgery as worth the sensory changes. ${ }^{26}$ The major predictor of post-SRS hypesthesia in a prior study was a cumulative radiation dose $>44 \mathrm{~Gy}$ to the lateral pons; the cumulative target dose and maximum brainstem dose did not reach statistical significance, however. ${ }^{26}$ Unfortunately, the optimal radiation dose to the target and to the brainstem has been varied across studies in the literature, $, 10,15,26,28,35$ and it remains controversial whether larger overall radiation doses are predictive of pain freedom after SRS. ${ }^{18,22}$ Some of the variability in cumulative radiation dosing is due in part to differences in study technique, including differences in outcome measures, inclusion of patients with atypical TN features, and follow-up duration. As a result, optimal cumulative target dose ranges from 115 to 150 Gy across the literature. This is similar to the dose range seen in our cohort of patients who received repeat SRS (the cumulative SRS dose ranged from 110 to $155 \mathrm{~Gy})$. Although some patients did receive relatively low doses at the time of repeat SRS, their overall doses were consistent with those reported in the literature. While larger doses of radiation at repeat SRS may have improved pain freedom rates, they could also have caused bothersome dysesthesias or anesthesia dolorosa, which were not experienced by any patient in this series. Besides delivering higher doses of radiation, Wolf and colleagues recently indicated that the ratio of dose to target nerve volume is predictive of pain freedom after SRS. ${ }^{38}$ Given that post-SRS hypesthesia has been described as the major predictor of pain freedom after repeat SRS in most published reports, future studies should aim to understand how cumulative dose to the lateral brainstem and dose to nerve volume correlate with nerve dysfunction and pain control outcome. Additional reports have suggested that facial numbness after first SRS is predictive of success af- ter a second SRS procedure; ${ }^{13,15}$ however, we found that all patients in our cohort who had facial sensory dysfunction after their first SRS regained that function prior to their second procedure and that it was not predictive of favorable outcome after repeat SRS.

\section{Conclusions}

Multiple surgical interventions exist for medically refractory TN, including the commonly pursued MVD and SRS. Patients often undergo SRS as a first-line therapy; however, residual or recurrent pain is common. In those patients in whom SRS has failed as a first-line surgical procedure, our data suggest that MVD is more likely to lead to a favorable pain outcome than repeat SRS. Still, in those patients in whom MVD carries too high of a risk profile, repeat SRS can lead to pain relief if post-SRS sensory changes are encountered. Although the overall small sample size in this study does limit its ability to be generalized, our data are consistent with the literature for firsttime MVD versus SRS, ${ }^{37}$ and we hope our experience will help counsel physicians and patients on treatment options after initial SRS fails to control their symptoms.

\section{References}

1. Al-Otaibi F, Alhindi H, Alhebshi A, Albloushi M, Baeesa S, Hodaie M: Histopathological effects of radiosurgery on a human trigeminal nerve. Surg Neurol Int 4 (Suppl 6):S462S467, 2014

2. Aubuchon AC, Chan MD, Lovato JF, Balamucki CJ, Ellis TL, Tatter SB, et al: Repeat gamma knife radiosurgery for trigeminal neuralgia. Int J Radiat Oncol Biol Phys 81:1059-1065, 2011

3. Barker FG II, Jannetta PJ, Bissonette DJ, Jho HD: Trigeminal numbness and tic relief after microvascular decompression for typical trigeminal neuralgia. Neurosurgery 40:39-45, 1997

4. Barker FG II, Jannetta PJ, Bissonette DJ, Larkins MV, Jho HD: The long-term outcome of microvascular decompression for trigeminal neuralgia. N Engl J Med 334:1077-1083, 1996

5. Bederson JB, Wilson CB: Evaluation of microvascular decompression and partial sensory rhizotomy in 252 cases of trigeminal neuralgia. J Neurosurg 71:359-367, 1989

6. Burchiel KJ: A new classification for facial pain. Neurosurgery 53:1164-1167, 2003

7. Burchiel KJ, Clarke H, Haglund M, Loeser JD: Long-term efficacy of microvascular decompression in trigeminal neuralgia. J Neurosurg 69:35-38, 1988

8. Chun-Cheng Q, Qing-Shi Z, Ji-Qing Z, Zhi-Gang W: A single-blinded pilot study assessing neurovascular contact by using high-resolution MR imaging in patients with trigeminal neuralgia. Eur J Radiol 69:459-463, 2009

9. Cohen J, Mousavi SH, Faraji AH, Akpinar B, Monaco EA, Flickinger JC, et al: Stereotactic radiosurgery as initial surgical management for elderly patients with trigeminal neuralgia. Stereotact Funct Neurosurg 95:158-165, 2017

10. Dvorak T, Finn A, Price LL, Mignano JE, Fitzek MM, Wu JK, et al: Retreatment of trigeminal neuralgia with Gamma Knife radiosurgery: is there an appropriate cumulative dose? Clinical article. J Neurosurg 111:359-364, 2009

11. Foy AB, Parisi JE, Pollock BE: Histologic analysis of a human trigeminal nerve after failed stereotactic radiosurgery: case report. Surg Neurol 68:655-659, 2007

12. Gorgulho A, De Salles AA, McArthur D, Agazaryan N, Medin P, Solberg T, et al: Brainstem and trigeminal nerve 
changes after radiosurgery for trigeminal pain. Surg Neurol 66:127-135, 2006

13. Helis CA, Lucas JT Jr, Bourland JD, Chan MD, Tatter SB, Laxton AW: Repeat radiosurgery for trigeminal neuralgia. Neurosurgery 77:755-761, 2015

14. Hodaie M, Chen DQ, Quan J, Laperriere N: Tractography delineates microstructural changes in the trigeminal nerve after focal radiosurgery for trigeminal neuralgia. PLoS One 7:e32745, 2012

15. Huang CF, Chiou SY, Wu MF, Tu HT, Liu WS: Gamma Knife surgery for recurrent or residual trigeminal neuralgia after a failed initial procedure. J Neurosurg 113 (Suppl):172-177, 2010

16. Jannetta PJ, McLaughlin MR, Casey KF: Technique of microvascular decompression. Technical note. Neurosurg Focus 18(5):E5, 2005

17. Kondziolka D, Lacomis D, Niranjan A, Mori Y, Maesawa S, Fellows W, et al: Histological effects of trigeminal nerve radiosurgery in a primate model: implications for trigeminal neuralgia radiosurgery. Neurosurgery 46:971-977, 2000

18. Kondziolka D, Zorro O, Lobato-Polo J, Kano H, Flannery TJ, Flickinger JC, et al: Gamma Knife stereotactic radiosurgery for idiopathic trigeminal neuralgia. J Neurosurg 112:758765,2010

19. Leal PR, Hermier M, Froment JC, Souza MA, Cristino-Filho G, Sindou M: Preoperative demonstration of the neurovascular compression characteristics with special emphasis on the degree of compression, using high-resolution magnetic resonance imaging: a prospective study, with comparison to surgical findings, in 100 consecutive patients who underwent microvascular decompression for trigeminal neuralgia. Acta Neurochir (Wien) 152:817-825, 2010

20. Leal PR, Hermier M, Souza MA, Cristino-Filho G, Froment JC, Sindou M: Visualization of vascular compression of the trigeminal nerve with high-resolution 3T MRI: a prospective study comparing preoperative imaging analysis to surgical findings in 40 consecutive patients who underwent microvascular decompression for trigeminal neuralgia. Neurosurgery 69:15-26, 2011

21. Linskey ME, Ratanatharathorn V, Peñagaricano J: A prospective cohort study of microvascular decompression and Gamma Knife surgery in patients with trigeminal neuralgia. J Neurosurg 109 (Suppl):160-172, 2008

22. Marshall K, Chan MD, McCoy TP, Aubuchon AC, Bourland $\mathrm{JD}$, McMullen KP, et al: Predictive variables for the successful treatment of trigeminal neuralgia with gamma knife radiosurgery. Neurosurgery 70:566-573, 2012

23. McLaughlin MR, Jannetta PJ, Clyde BL, Subach BR, Comey $\mathrm{CH}$, Resnick DK: Microvascular decompression of cranial nerves: lessons learned after 4400 operations. J Neurosurg 90:1-8, 1999

24. Miller JP, Acar F, Burchiel KJ: Classification of trigeminal neuralgia: clinical, therapeutic, and prognostic implications in a series of 144 patients undergoing microvascular decompression. J Neurosurg 111:1231-1234, 2009

25. Miller JP, Magill ST, Acar F, Burchiel KJ: Predictors of longterm success after microvascular decompression for trigeminal neuralgia. J Neurosurg 110:620-626, 2009

26. Park KJ, Kondziolka D, Berkowitz O, Kano H, Novotny J Jr, Niranjan A, et al: Repeat gamma knife radiosurgery for trigeminal neuralgia. Neurosurgery 70:295-305, 2012

27. Pollock BE: Comparison of posterior fossa exploration and stereotactic radiosurgery in patients with previously nonsurgically treated idiopathic trigeminal neuralgia. Neurosurg Focus 18(5):E6, 2005

28. Pollock BE, Foote RL, Stafford SL, Link MJ, Gorman DA, Schomberg PJ: Results of repeated gamma knife radiosurgery for medically unresponsive trigeminal neuralgia. J Neurosurg 93 (Suppl 3):162-164, 2000
29. Régis J, Tuleasca C, Resseguier N, Carron R, Donnet A, Gaudart J, et al: Long-term safety and efficacy of Gamma Knife surgery in classical trigeminal neuralgia: a 497-patient historical cohort study. J Neurosurg 124:1079-1087, 2016

30. Riesenburger RI, Hwang SW, Schirmer CM, Zerris V, Wu JK, Mahn K, et al: Outcomes following single-treatment Gamma Knife surgery for trigeminal neuralgia with a minimum 3-year follow-up. J Neurosurg 112:766-771, 2010

31. Rogers CL, Shetter AG, Fiedler JA, Smith KA, Han PP, Speiser BL: Gamma knife radiosurgery for trigeminal neuralgia: the initial experience of The Barrow Neurological Institute. Int J Radiat Oncol Biol Phys 47:1013-1019, 2000

32. Sarsam Z, Garcia-Fiñana M, Nurmikko TJ, Varma TR, Eldridge P: The long-term outcome of microvascular decompression for trigeminal neuralgia. Br J Neurosurg 24:18-25, 2010

33. Sekula RF Jr, Frederickson AM, Jannetta PJ, Quigley MR, Aziz KM, Arnone GD: Microvascular decompression for elderly patients with trigeminal neuralgia: a prospective study and systematic review with meta-analysis. J Neurosurg 114:172-179, 2011

34. Tatli M, Satici O, Kanpolat Y, Sindou M: Various surgical modalities for trigeminal neuralgia: literature study of respective long-term outcomes. Acta Neurochir (Wien) 150:243-255, 2008

35. Tuleasca C, Carron R, Resseguier N, Donnet A, Roussel P, Gaudart J, et al: Repeat Gamma Knife surgery for recurrent trigeminal neuralgia: long-term outcomes and systematic review. J Neurosurg 121 (Suppl):210-221, 2014

36. Tyler-Kabara EC, Kassam AB, Horowitz MH, Urgo L, Hadjipanayis C, Levy EI, et al: Predictors of outcome in surgically managed patients with typical and atypical trigeminal neuralgia: comparison of results following microvascular decompression. J Neurosurg 96:527-531, 2002

37. Wang DD, Raygor KP, Cage TA, Ward MM, Westcott S, Barbaro NM, et al: Prospective comparison of long-term pain relief rates after first-time microvascular decompression and stereotactic radiosurgery for trigeminal neuralgia. J Neurosurg 128:68-77, 2018

38. Wolf A, Tyburczy A, Ye JC, Fatterpekar G, Silverman JS, Kondziolka D: The relationship of dose to nerve volume in predicting pain recurrence after stereotactic radiosurgery in trigeminal neuralgia. J Neurosurg 128:891-896, 2018

39. Zeng Q, Zhou Q, Liu Z, Li C, Ni S, Xue F: Preoperative detection of the neurovascular relationship in trigeminal neuralgia using three-dimensional fast imaging employing steady-state acquisition (FIESTA) and magnetic resonance angiography (MRA). J Clin Neurosci 20:107-111, 2013

\section{Disclosures}

The authors report no conflict of interest concerning the materials or methods used in this study or the findings specified in this paper.

\section{Author Contributions}

Conception and design: Raygor. Acquisition of data: Raygor, Wang, Ward, Barbaro. Analysis and interpretation of data: Raygor. Drafting the article: Raygor. Critically revising the article: all authors. Reviewed submitted version of manuscript: Chang, Raygor. Statistical analysis: Raygor. Administrative/technical/material support: Ward. Study supervision: Chang.

\section{Correspondence}

Edward F. Chang: University of California, San Francisco, CA. edward.chang@ucsf.edu. 